\title{
Commentary: Are two local therapies better than one for early-stage small cell lung cancer?
}

\author{
Chukwumere E. Nwogu, MD, PhD
}

\author{
From the Department of Thoracic Surgery, Roswell Park Comprehensive Cancer Center, Buffalo, NY; and \\ Department of Surgery, Jacobs School of Medicine and Biomedical Sciences, University at Buffalo, NY. \\ Disclosures: Author has nothing to disclose with regard to commercial support. \\ Received for publication Sept 18, 2019; revisions received Sept 18, 2019; accepted for publication Sept 18, 2019 \\ Address for reprints: Chukwumere E. Nwogu, MD, PhD, Department of Thoracic Surgery, Roswell Park Compre- \\ hensive Cancer Center, Elm and Carlton Sts, Buffalo, NY 14263 (E-mail: Chumy.nwogu@ roswellpark.org). \\ J Thorac Cardiovasc Surg 2019;158:1679 \\ $0022-5223 / \$ 36.00$ \\ Copyright (C) 2019 Published by Elsevier Inc. on behalf of The American Association for Thoracic Surgery \\ https://doi.org/10.1016/j.jtcvs.2019.09.041
}

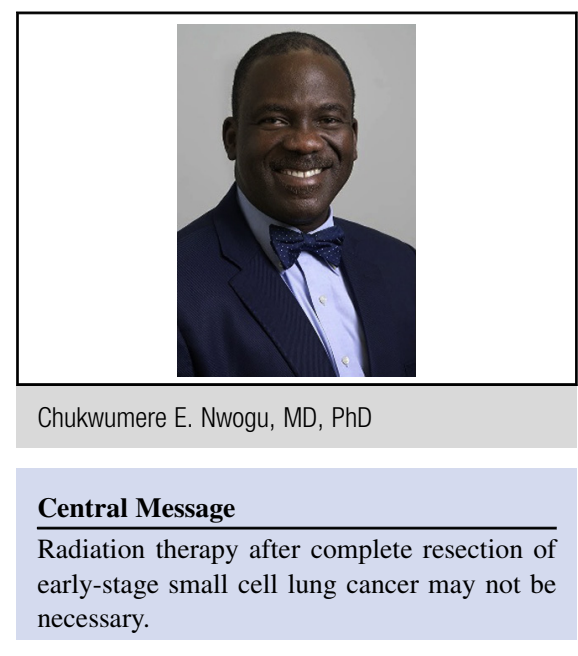

See Article page 1665 .
In this era of lung cancer screening with low-dose computed tomography, a growing proportion of the practice of thoracic surgeons will probably involve the management of localized pulmonary nodules. On the basis of historical trends, although $85 \%$ of malignant lesions will be nonsmall cell lung cancer, a sizeable minority (15\%) will be small cell lung cancer (SCLC). When SCLC is localized and without lymph node involvement, surgical resection is recommended by the National Comprehensive Cancer Network guidelines. It is essential for thoracic surgeons to fully appreciate the evidence-based, appropriate adjuvant therapy that is indicated after such resections. The article by Engelhardt and colleagues ${ }^{1}$ in this issue of the Journal is therefore a timely contribution. Both surgery and radiotherapy are local therapies, in contrast to systemic modalities, such as chemotherapy. Is there value in applying 2 local therapies plus chemotherapy to a single patient, rather than the combination of a local and a systemic therapeutic modality? Engelhardt and colleagues ${ }^{1}$ sought to answer this question by assessing overall survival after surgical resection of early-stage SCLC with or without adjuvant thoracic radiation in a retrospective cohort from the $\mathrm{Na}$ tional Cancer Database. In both the matched and unmatched cohorts of patients with T1/2N0M0 SCLC, there was no statistically significant difference in overall survival between the groups, and thus no benefit from postoperative thoracic radiotherapy could be demonstrated.

It is quite interesting that the National Cancer Database defines thoracic radiotherapy as radiotherapy directed at the region of the lung without nodal irradiation. Specifically, this definition excludes hilar, mediastinal, or supraclavicular nodes. ${ }^{1}$ These nodal basins are potential sites of 